\title{
Uluslararası ortopedi ve travmatoloji birliklerinde genç Türk ortopedistlerin rolü ve firsatlar
}

\section{The roles and opportunities for young Turkish orthopedic surgeons in international orthopaedics and traumatology associations}

\author{
Fatih Küçükdurmaz ${ }^{1,2}$, Gazi Huri ${ }^{3}$ \\ ${ }^{1}$ Post Doc Research Fellow, The Rothman Institute at Thomas Jefferson University, \\ Department of Orthopaedic Research, Hip \& Knee Arthroplasty \\ ${ }^{2}$ Bezmialem Vakıf Üniversitesi Tıp Fakültesi, Ortopedi ve Travmatoloji Anabilim Dalı, İstanbul \\ ${ }^{3}$ Hacettepe Üniversitesi Tıp Fakültesi, Ortopedi ve Travmatoloji Anabilim Dalı, Ankara
}

U

luslararası mesleki platformlarda bulunmak, farklı bakış açıları yakalamamızı, sınırlı başarılarımızın dışında kocaman bir dünya olduğunun farkına varmamızı sağlar. Bu yönüyle uluslararası mesleki kuruluşlar, mesleğimizin sınır tanımaz özelliğinin bir nimetidir ve bizler için bilimin ışığına açılan daha geniş bir pencere olarak da düşünülebilir. Günümüzde alt dallara veya coğrafi alanlara göre kurulmuş pek çok mesleki birlik bulunmaktadır.

Meseleyi uluslararası ortamlarda ülkemizin temsili açısından da değerlendirmek gerekir. Bilginin paylaşılmasının ve ülkemizin temsilinin, ekonomik, sosyal ve kültürel sonuçları olduğunu da hatırda tutmak gerekir. Halihazırda ortaya konan yoğun çabalara rağmen, ülkemizin potansiyeli ve layık olduğu yer göz önünde bulundurulursa, daha çok çalışmamız gerektiği ortadadır. İşte bu aşamada genç meslektaşlarımıza önemli roller düşmektedir.

Bu yazıda, ülkemizde bilinirliği açısından en önde gelen iki uluslararası meslek kuruluşunun (SICOT ve EFORT) genç üyelerine yönelik oluşturdukları grupları ve ülkemizden genç meslektaşlarımız için bu grupların mevcut yapılarını ve sunduğu firsatları özetlemeye çalıştık. Umarız bu yazımız "kutunun dışı"na çıkmak isteyen genç meslektaşlarımız açısından faydalı olur.

\section{SICOT Genç Cerrahlar Komitesi}

Société Internationale de Chirurgie Orthopédique et de Traumatologie (SICOT), merkezi Brüksel'de bulunan ve sivil toplum kuruluşu statüsünde bir meslek birliğidir. 1929 yılında Paris'te kurulmuştur. Halihazırda,
Türkiye'nin de dahil olduğu 110 ülkenin temsil edildiği bir global birliktir. SICOT, son derece iyi organize olmuş bir yapı gösterir. Coğrafi kapsam açısından, dünyanın en yaygın SICOT faaliyetlerini ihdas ettiği komiteler yoluyla gerçekleştirir. Bu komiteler iki grup altında toplanır: 1) ortopedi ve travmatolojinin alt branşlarının komiteleri (kalça cerrahisi, diz cerrahisi, pediatrik ortopedi vb.) ve 2) idari komiteler (finans, genişleme, kongre vs. komiteleri). Bu komitelerden biri de Genç Cerrahlar Komitesi'dir.

Genç Cerrahlar Komitesi (GCK) 2001 yılında kurulmuştur. Illk kurulduğu yıllarda organizasyonunu tamamlamaya çalışmış, daha sonra Dr.Cyril Toma ve Dr.Hatem Said başkanlığında daha etkin hale getirilmiştir. Bu komitenin başkanlığını 2012 yılından beri Dr. Fatih Küçükdurmaz yürütmektedir. Son iki yıldır GCK kendi iç yapılanmasını sistematik hale getirmek üzere çalışmalar yapmaktadır. Halen 20 aktif üyesi olan komitede üyeler, aktivite, katkı ve katılım durumlarına göre farklı üç üyelik statüsü altında toplanmıştır ve üyelikler her yıl güncellenmektedir. GCK yönetim kurulu dokuz üyeden oluşmaktadır. Bütün üyeler GCK yapısı içerisinde oluşturulmuş takımlardan birinde aktif olmak durumundadır. GCK'yı oluşturan takımlar şunlardır:

\section{SIGNEL takımı}

SIGNEL, "SICOT Global Network of Electronic Learning" anlamına gelir. SICOT'un 2011'den beri yapılmış olan kapsamlı veya yerel pek çok toplantısındaki sunumları, webinar'ları ve benzeri eğitim dökümanlarını bünyesinde barındıran, basit bir arama motoru ile istenilen

- Illetişim adresi: Assist. Prof. Dr. Fatih Küçükdurmaz, The Rothman Institute at Thomas Jefferson University, Department of Orthopaedic Research, Philadelphia, PA, USA Tel: +1 (215) 8087320 e-posta: fatihmfk@hotmail.com

- Geliș tarihi: 24 Ekim 2014 Kabul tarihi: 24 Ekim 2014 
konulara ulaşılabilen, sunumların çeşitli kategorilerde tasnif edildiği bir veritabanıdır. ${ }^{[1]}$ Her geçen gün büyümekte olan bu çevirimiçi platform, içerik ve kullanım özellikleri açısından GCK'nin yönettiği bir eğitim aracıdır.

\section{Kongre takımı}

Her yıl düzenlenen kongrelerde, genç meslektaşlarımızın da toplantılardaki sempozyum, kurs ve sunumların organizasyonunda rol almalarında ya da bazılarının tamamen kendileri tarafından organize edilmesinde etkin bir komitedir. SICOT'un 2014 kongresinde, bu komitenin katkıları ile altı sempozyum, ve bir kurs düzenlenmiştir. Bu oturumlara, konularında uzman ve tanınmış pek çok önemli isim davet edilmiş, GCK üyeleri bazı oturumlarda konuşmacılar arasında yer almış veya moderatörlük yapmışlardır. Çok cesaretlendirici geribildirimlerin alındığı bu komitenin faaliyetleri, 2015'te Çin'in Guangzhau şehrinde yapılacak olan kongrede artarak devam edecektir.

\section{Webinar takımı}

Çevirimiçi eğitim yöntemleri ve materyallerinin giderek yaygınlaştığı günümüzde, GCK, alanında dünya lideri olan VuMedi ile işbirliği içerisinde, seçilmiş konularda webinar'lar düzenlemektedir. ${ }^{[2]}$ Son derece önemli isimlerin katılımı ile gerçekleştirilen webinar'lar eşzamanlı olarak dünyanın pek çok coğrafı bölgesinden katılımcının da dahil olması ile, interaktif bir şekilde yapılabilir. Ayrıca, bu webinar'lar VuMedi'nin kendi sitesindeve SIGNEL platformunda da arşivlenir. ${ }^{[3]} \mathrm{Bu}$ şekilde, webinar'ların istendiği zaman izlenmesi mümkün olabilmektedir.

\section{Kadın ortopedi ve travmatologlar takımı}

Komitemizin en aktif grubunu kadın meslektaşlarımız oluşturmaktadır. Bu komitenin amacı, global bir grup ve çok sayıdaki başarılı kadın ortopedi ve travmatoloji hekimi arasında bir ağ oluşturmaktır.

\section{Sosyal medya takımı}

Halen Facebook ve Linkedin'de "YSC" aktif bir gruba sahiptir. Grupta, olgu paylaşımları, toplantı ve benzeri mesleki faaliyet duyuruları ve SICOT ile ilgili güncellemeler yapılır.

\section{Eğitim kursu takımı}

Yıllık olarak yapılan SICOT kongrelerinden bir gün önce ve tam gün olarak, "Educational Day" ismiyle yoğun bir kurs yapılır. ${ }^{[4]}$ Her yıl bir tema belirlenir (omuz, kalça, diz vb.) ve o konuda uzmanlaşmış ortopedi ve travmatoloji cerrahları tarafından hızlandırılmış, yoğun ve güncel bilgiler dinleyicilere aktarılır. Sunumları yapanlar, mesleğin duayenleri ve genç nesil uzmanlardan dengeli bir şekilde seçilir. Böylece genç meslektaşlarımız için kongrelere sadece dinleyici olarak değil, konuşmacı olarak katılma firsatları oluşturulur. Bu durum, genç cerrahlar açısından motivasyon arttırıcı bir etmen olmanın yanı sıra, SICOT kongresine de bir dinamizm getirmektedir.

\section{SICOT Genç Cerrahlar Komitesi'nde rol almak}

SICOT-GCK, uluslararası platformlarda aktif olmak isteyen, 40 yaş altındaki bütün meslektaşlarımıza açıktır. GCK komite toplantıları, kongreler sırasında herkese açık olarak yapılır ve her görüş ve katkıya eşit fırsat tanınır. Özellikle iletişim teknolojileri ile ortopedi ve travmatoloji eğitimi üzerine görüşler arasından uygulanabilirliği olanlar, bir rapor olarak SICOT yönetim kuruluna bir teklif olarak sunulur ve sıklıkla uygulamaya geçer. Bu süreçler, yeni fikirlerin üretimi, bunların uygulanmasında inisiyatif alma, kendini geliştirme ve global bir ağ oluşturma motivasyonu taşıyan genç meslektaşlarımız için eşsiz fırsatlar sunmaktadır. Komitemiz, genç meslektaşlarımız açısından kolay ulaşılabilir, bürokratik katmanlaşmalardan uzak, pratik sonuçları olan yararlı girişimlere açık olmaya özen gösterir. Ülkemizden genç meslektaşlarımızın bu komitede daha fazla rol alması son derece önemlidir. Mesleğimizin evrenselliğinden esinlenerek, kalıpların dışına çıkmak isteyen, bu uluslararası platformda fikir ve heyecanlarını bizimle paylaşacak, çok sayıda arkadaşımızın olduğuna eminiz; bu arkadaşlarımızı komitemizde görmekten son derece mutluluk duyarız.

\section{FORTE}

\section{(Federation of Orthopaedics Trainees in Europe)}

Uluslararası sivil toplum kuruluşlarını oluşturan Dünya devletlerinin; tarihi, siyasi, ekonomik ve hukuki yapısı ile işleyişleri gibi konulardaki farklılıklar, bu derneklerde görev almak ve başarıya ulaşmak konusunda bazı güçlüklerle karşılaşılmasına neden olabilmektedir. Günümüz iletişim çağında, her ne kadar uluslararası bilimsel, ekonomik ve kültürel sınırlar kalkmış olsa da, Dünya'da asırlardır geçerliliğini sürdürmüş ve uluslararası iletişimde başarının sırları olarak tanımlanan bazı gerçekleri göz ardı edemeyiz; çünkü, uluslararası bilimsel camiada ihtiyacımı olan, akademik bilgilerimizin yanı sıra sosyal ilgilerimizdir. Bu bağlamda ilk olarak M.Ö. 412-323 yıllarında "Sinop'lu Diyojen" tarafından ortaya atılan "Dünya vatandaşlığı" kavramı önem kazanmaktadır. ${ }^{[5]}$ Bu kavramda kişi, özüne ait her şeyi muhafaza ederek evrensel değerlerle bütünleşir ve hayata geçirir. Yüzlerce yıl önce yaşamış olmasına rağmen 
öğretileri halen geçerli olan Sokrates, Thomas Paine ve Albert Einstein gibi büyük düşünürler de "Dünya vatandaşlığı" kavramını düşüncelerinin merkezine yerleştirmişlerdir. Dünya vatandaşlığının temelinde evrensel doğrular yatar. Eğer birey bu evrensel doğrular kılavuzluğunda ilerlemeyi başarabilirse, uluslararası ilişkiler kavramını da insan-insan ilişkisine indirger ve başarılı olma şansını arttırır.

Ülkemizde TOTBID (Türk Ortopedi ve Travmatoloji Birliği Derneği) Yönetim Kurulu'nun 2012 yılında almış olduğu yönetim kurulu kararı ile kurulan TOTBID-AGUH (TOTBID - Asistan ve Genç Uzman Hekim) Konseyi, Türkiye'de ortopedi asistan ve genç uzmanların kendi iradeleri ile oluşturdukları bir topluluk olarak faaliyetlerine başlamıştır. TOTBiD-AGUH'nin ilk faaliyetlerden biri; Avrupa genelinde uzmanlık eğitiminde ortak paydanın oluşturulması, eğitimin optimizasyonu ve standardizasyonu için, söylemlerimizi ve fikirlerimizi uluslararası da paylaşabileceğimiz, 2005 yılından bu yana faaliyet gösteren "Federation of Orthopaedics Trainees in Europe - FORTE”ye 2012 ilk yarısında Avrupa'daki 17. ülke olarak "ülke üyeliği"nin kabul edilmesidir. Aynı yıl, Ekim ayında düzenlenen 11. Türk Spor Yaralanmaları Artroskopi ve Diz Cerrahisi Kongresi'nde, TOTBID-AGUH'nin katkıları ile bilimsel içeriği güçlü, yoğun katılım sağlanan, FORTE özel oturumu gerçekleştirilmiştir. İstanbul'da 2013 yılında düzenlenen EFORT kongresinde, FORTE TOTBID-AGUH işbirliği ile organize edilen FORTE oturumunda, genç meslektaşlarımızın yoğun katılımı ile etkin bir tartışma ortamı sağlanmış ve toplantı büyük bir başarı ile sonuçlanmıştır. Haziran 2014'te Londra'da düzenlenen EFORT 2014 toplantısında yapılan FORTE oturumunda, yeni yönetim kurulu seçimi gerçekleşmiş ve Ülkemizin temsilcisi FORTE başkanlığına seçilmiştir. Bu sayede TOTBID-AGUH'un da uluslararası platformlarda daha etkin bir şekilde yer alması sağlanmış, FORTE yönetim kurulu ve diğer kurulları kapsamında Ülkemize toplam üç temsilcilik verilmiştir. Önemli sayıdaki bu temsilcilikler, FORTE'nin gelecek projelerinde Ülkemizin daha da aktif rol alabilmesine olanak sağlayacaktır.

Ortopedi alanındaki uluslararası ilişkiler, akademik bilgilerin gelişmesinde, farklı yaklaşımların öğrenilmesinde ve çok merkezli yapılan araştırmaların parçası olabilmek konularında da etkili bir işbirliği sağlar. Bu bağlamda, 19-20 Şubat 2015 tarihinde, EFORT Merkez Ofisi, Rolle, İsviçre'de ülkemizin başkanlık yapacağı Avrupa'nın genç ortopedi temsilcilerini bir araya getirecek olan 'FORTE Summit 2015" toplantısı gerçekleştirilecektir. Toplantıya ülkemizi temsilen AGUH
Yönetim Kurulu Başkanı'nın katılması planlanmaktadır. Toplantının ana hedeflerinden biri, Avrupa'daki diğer genç ortopedi dernekleri ile işbirliği içerisinde, Avrupa Birliği Erasmus+ Çerçeve Programları doğrultusunda proje oluşturulmasıdır. Oluşturulacak olan bu eğitim projesinde TOTBID-AGUH'nin, projenin liderliğini üstlenmesi öngörülmektedir.

Bilim alanımızdaki uluslararası bağlantıların, sadece bilimsel açıdan değil, aynı zamanda global doğruları takip ederek kişisel ve iş disiplininin sağlanmasında da önemli rol oynadığı gösterilmiştir. Günümüzde, uluslararası kuruluşların ve derneklerin evrensel doğruların öğrenilmesinde önemli bir firsat olabileceği savunulmaktadır. Evrensel doğru denilince, akla "insanlığın ilk dönemlerinden beri, uygulanması kazanımlarla sonuçlanmış davranışların birleşimi” tanımı gelmektedir. Peki, evrensel doğruların öğrenilmesi bizlere neler katar?

1. Hayal dünyasında yaşamadan, hayal kurmamızı sağlar.

2. Hedeflerimizin özgün, özerk, ölçülebilir, gerçekçi, uygulanabilir ve zamanlı olmasını öğretir.

3. Varmak istediğimiz noktayı önceden belirlememizde yol gösterici olur.

4. Dinlemeyi, anlamayı ve fikirlerimizi paylaşmayı öğretir.

5. Mesleki sorumluluk hissimizin gelişmesinde oldukça etkilidir.

6. Soru sormaktan vazgeçmememiz gerektiğini vurgular.

7. Sınırlarımızı zorlamamızı ve bu bağlamda inançlı olmamızı sağlar. Hata yapmaktan korkmamamızı öğretir.

8. Uluslararası platformlarda, mesleki bazda bizlere rol model olabilecek duayenlerle tanışma imkânı sağlar.

9. Özellikle farklı kültür, bölge ve görüşlerden insanlarla aynı masa etrafında konuşmamıza imkân tanır.

Bu denli kazanımların elde edilebileceği uluslararası ilişkiler içerisinde bulunabilme fırsatına sahip olmak, kişilerde bazı gereksinimler doğurur. Öncelikle, yapılacak her aktiviteyi bilimsel veriler ışığında gerçekleştirmek, kişinin saygınlığını ve o kişiye duyulan güveni arttırır. Lakin, topluluklarda güven olmadan başarıya ulaşmak imkânsızdır. Bununla birlikte, yabancı kültürlere uyum göstermek, saygı duymak ve kabullenmek, öncelikle kişinin kendi kültürünü yüceltecek ve işbirliğini olanaklarını arttıracaktır. Ayrıca, ortopedi biliminin gelişmelerini takip etme ve güncel olma adına ileri seviyede yabancı dil bilmek vazgeçilmez bir gereksinimdir. 
Bunun yanı sıra, kişinin bulunduğu topluluğu iyi analiz etmesi ve yapılmayanları belirleyip onlara yönelik projeler üretmesi, uluslararası derneklerde saygın pozisyonlara gelmesi için oldukça önemlidir. Çünkü günümüzde, uluslararası arenada kişi sadece ürettikleri ile söz sahibi olabilir. Bu bağlamda, TOTBiDAGUH'nin bundan sonra FORTE ile beraber yürüteceği çalışmalarında, bu konuya özellikle eğilmesi amaçlanmaktadır.

\section{KAYNAKLAR}

1. SIGNEL. http://www.sicot.org/signel

2. SICOT-VuMedi webinars. http://www.sicot.org/vumedi

3. VuMedi. https://www.vumedi.com/channel/sicot/

4. Khanduja V. The SICOT Educational Day. http://sicot.org/ resources/File/Education\%20and\%20Training/SICOT\%20 Educational\%20Day.pdf

5. Laertius D. The Lives of Eminent Philosophers. Chapter VI, line 63. Çev. Hicks RD. Loeb Classical Library; 1925. 